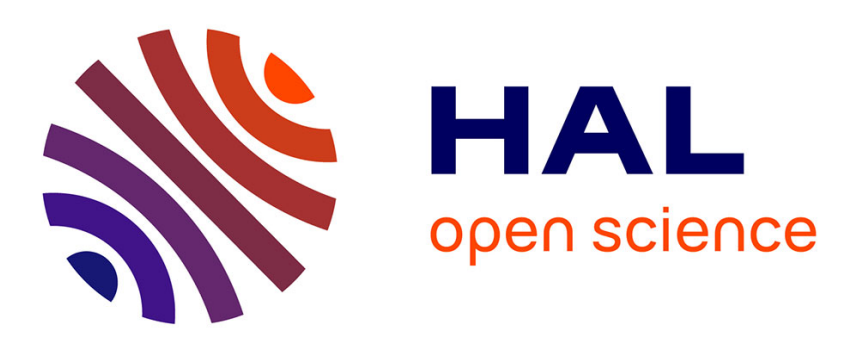

\title{
Intermediate band in the gap of photosensitive hybrid gel based on titanium oxide: role of coordinated ligands during photoreduction
}

Thomas Cottineau, Annabelle Rouet, Vincent Fernandez, Luc Brohan, Mireille Richard-Plouet

\section{To cite this version:}

Thomas Cottineau, Annabelle Rouet, Vincent Fernandez, Luc Brohan, Mireille Richard-Plouet. Intermediate band in the gap of photosensitive hybrid gel based on titanium oxide: role of coordinated ligands during photoreduction. Journal of Materials Chemistry A, 2014, 2 (29), pp.11499-11508. 10.1039/c4ta02127d . hal-02384175

\section{HAL Id: hal-02384175 \\ https://hal.science/hal-02384175}

Submitted on 28 Nov 2019

HAL is a multi-disciplinary open access archive for the deposit and dissemination of scientific research documents, whether they are published or not. The documents may come from teaching and research institutions in France or abroad, or from public or private research centers.
L'archive ouverte pluridisciplinaire HAL, est destinée au dépôt et à la diffusion de documents scientifiques de niveau recherche, publiés ou non, émanant des établissements d'enseignement et de recherche français ou étrangers, des laboratoires publics ou privés. 


\title{
Intermediate Band in the Gap of Photosensitive Hybrid Gel Based on Titanium Oxide: Role of Coordinated Ligands During Photoreduction. ${ }^{\dagger}$
}

\author{
Thomas Cottineau, ${ }^{* a, b}$ Annabelle Rouet, ${ }^{a, c}$ Vincent Fernandez, ${ }^{a}$ Luc Brohan ${ }^{a}$ and Mireille Richard- \\ Plouet* $^{* a}$
}

\author{
${ }_{5}$ Received (in $\left.X X X, X X X\right)$ Xth $X X X X X X X X X 20 X X$, Accepted Xth XXXXXXXXX 20XX \\ DOI: $10.1039 / b 000000 x$
}

\begin{abstract}
UV light induced chemical modifications of a new hybrid organic-inorganic gel, based on titanium oxide and obtained by a soft chemistry method, are studied by XPS and UV-visible spectroscopy. XPS experiments, with an in situ UV illumination design, were performed in order to study the different 10 chemical modifications of the gel. The $\mathrm{Ti}^{4+}$ to $\mathrm{Ti}^{3+}$ reduction, as well as the associated change in the ligands coordinating titanium cations, are accompanied by a deprotonation of the molecules in the vicinity of the inorganic part. In the meantime, an intermediate band arises in the gap just below the Fermi level. The appearance of this band correlates with the light absorption properties of the gel as measured by UVvisible spectroscopy. Following on from these experiments, a complete band diagram of the electronic 15 structure is proposed in order to clarify the position of this intermediate band. These distinctive properties suggest that the nanostructured hybrid gel could be used as a new class of intermediate band material that can be synthesized at low cost for photovoltaic applications.
\end{abstract}

\section{Introduction}

Solar energy harvesting is one of the most interesting approaches 20 towards fulfilling the need for a clean energy supply. It is an inexhaustible, decentralized natural resource, and the solar power reaching the earth is far greater than actual energy consumption. ${ }^{1}$ Photovoltaic (PV) conversion requires a relatively low land occupation (e.g. compared to biomass) in order to convert solar 25 energy into electricity, and should thus become a major source of electricity. ${ }^{2}$ However, even though some PV systems are very efficient, the electricity produced generally remains more expensive than that produced by traditional technologies based on the use of fossil fuels. Future development of the PV industry 30 therefore hinges upon the discovery of alternative, low-cost materials and concepts that promote an increase in the efficiency of PV systems over and above the Queisser-Schokley limit of the p-n junction PV cell (max. efficiency $\approx 34 \%$ ). ${ }^{3}$

Currently, several innovative concepts exist proposing the 35 development of third-generation PV solar cells that can overcome this limit, such as down- and up-conversion, ${ }^{4,5}$ multiple electron generation ${ }^{6}$ or a multijunction PV cell. ${ }^{7}$ The lattermost PV system holds the world record for conversion efficiency $(44.4 \%$ under

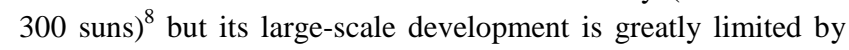
40 the cost and complexity of device manufacture. Among these new approaches we find the intermediate-band solar cell (IBSC), which is a device based on a single material that could absorb photons in different energy ranges while maintaining an elevated output voltage, in order to obtain a high level of efficiency. ${ }^{9}$ This 45 concept is based on the presence of an intermediate band (IB) in the gap of a semiconductor. ${ }^{10}$ In addition to the usual band gap absorption, this intermediate band should permit the absorption of photons with an energy below the band gap, i.e. between the valence band (VB) and the IB, as well as between the IB and the 50 conduction band $(\mathrm{CB})$.

The first proposed approach for obtaining IB material systems was based on quantum dots of a small band gap material dispersed in the matrix of a large band gap semiconductor. ${ }^{11}$ Even though the concept of an intermediate band solar cell was 55 confirmed (below ambient temperature), the cost associated with the production methods of this system is considered to be too high for commercial development. ${ }^{12}$ Nowadays, a large part of the work in this domain is devoted to finding bulk IB materials. ${ }^{13}$ From $a b$ initio studies, different materials with potentially high ${ }_{60}$ photovoltaic efficiency were identified, ${ }^{14}$ and different concepts are proposed, such as semiconductor alloys, ${ }^{15}$ semiconductor superlattices $^{16}$ or non-compensated n-p co-doping of large band gap semiconductors. ${ }^{17}$ Nevertheless, to the best of our knowledge, no clear evidence of the presence of an intermediate 65 band was reported at room temperature, and the overall efficiency of IB solar cells does not reach the expected high conversion yield. ${ }^{13}$ New materials and concepts have yet to be identified with respect to this particular application.

Recent advances in nanomaterial synthesis offer smart options 70 for innovative energy conversion and storage materials. In particular, the development of hybrid organic-inorganic materials with distinctive properties that provide new prospects when integrated into PV devices. ${ }^{18}$ These materials blend the diversity and processability of organic molecules or polymers together 75 with the favorable electronic and optoelectronic properties of inorganic semiconductors. The enhanced surface area to volume 
ratio of nanostructured materials leads to the predominance of surface states inducing enhanced photochemical effects that differ tremendously from their bulk counterparts. ${ }^{19,20}$ They also offer cost-efficient production prospects with respect to high5 performance electronic and optoelectronic devices.

This study details the properties of a hybrid organic-inorganic gel, under UV illumination, which might be used as a new class of intermediate band material synthesized at low cost and at room temperature. This material is based on a nanostructured titanium 10 oxide inorganic network in strong interaction with the surrounding organic molecules. $\mathrm{TiO}_{2}$ nano-objects are already used in various photochemical applications, such as photocatalysis, $^{21}$ photoelectrochemical $^{22}$ and PV solar cells. ${ }^{23}$ $\mathrm{TiO}_{2}$ provides an attractive option for green technologies due to 15 its natural abundance on earth, chemical stability and ease of synthesis at low cost. However, due to a bandgap of $3.1 \mathrm{eV}$, it absorbs less than $5 \%$ of the solar spectrum. ${ }^{24}$ Our new synthesis method involves an inorganic reactant, as a precursor for $\mathrm{Ti}$ cations, that is hydrolyzed by an organic solvent such as N,N20 dimethylformamide (DMF). ${ }^{25,26}$ Even though the formation mechanism and the structural model of these sols and gels are known, ${ }^{27}$ the origin of their interesting properties under illumination is not yet fully understood. Indeed, these sols and gels are photosensitive and become dark blue under UV 25 illumination. EPR experiments indicate the reduction of $\mathrm{Ti}^{4+}$ to $\mathrm{Ti}^{3+}$ which is accompanied by a change in the nature of the ligands around the Ti cations. ${ }^{28,29}$ Nevertheless, the role of the organic matrix in the sensitivity mechanism is still unclear. Here we present new XPS results obtained on the hybrid titanium 30 oxide gel, and their evolution under in-situ UV illumination. Experimental results indicate that photoinduced chemical modifications on the organic and inorganic parts of the gel generate an intermediate band within its band gap, just below the Fermi level. UV-visible absorption spectra of the gel, after 35 photoinduced modification, are used to clarify the position of this intermediate band.

\section{Experimental}

\section{TiDMF gel synthesis}

The hybrid sol and gel are synthesized using anhydrous N,N40 dimethylformamide (noted DMF; $\left(\mathrm{CH}_{3}\right)_{2} \mathrm{NCHO}, 99.8 \%$, Aldrich) and the titanium oxychloride solution is stabilized in an acidic medium $\left(\mathrm{TiOCl}_{2} \cdot 1.4 \mathrm{HCl} \cdot 7 \mathrm{H}_{2} \mathrm{O}, 4.85 \mathrm{~mol} \mathrm{~L}^{-1}\right.$ in titanium, Cristal Global). The sol is prepared by adding droplets of DMF $(12 \mathrm{~mL})$ to an ice-cooled $\mathrm{TiOCl}_{2}$ solution $(5 \mathrm{~mL})$ under 45 continuous stirring. The mixture is then stored in a closed container at $70^{\circ} \mathrm{C}$, and 24 hours later a transparent, waxy solid (denoted TiDMF gel) is obtained.

\section{XPS with in situ UV illumination}

XPS experiments were conducted on TiDMF gel which was ${ }_{50}$ deposited on a glass slide. In order to avoid analyzer contamination due to massive desorption, the gel was deposited in the form of a thin layer $(<0.1 \mathrm{~mm})$ on a surface of $5 * 5 \mathrm{~mm}^{2}$. The solvent part of the gel, unbound to the $\mathrm{TiO}_{2}$ network, is evacuated in the pre-chamber in which the pressure decreases 55 down to $5.10^{-5} \mathrm{~Pa}$.
The XPS spectra were recorded on a Kratos Axis Ultra photoelectron spectrometer using a monochromatic Al Ka source $(1486.6 \mathrm{eV})$ operating at $150 \mathrm{~W}$. The pressure in the analysis chamber was always kept below $6 \cdot 7 \cdot 10^{-7} \mathrm{~Pa}$. Due to the insulating 60 nature of the sample, charge compensation was accomplished using a low-energy electron flow gun. Survey spectra were measured from -2 to $1200 \mathrm{eV}$, using constant pass energy of 160 eV. High-resolution spectra of $\mathrm{O} 1 \mathrm{~s}, \mathrm{Ti} 2 \mathrm{p}_{3 / 2}, \mathrm{~N} 1 \mathrm{~s}, \mathrm{C} 1 \mathrm{~s}$, and $\mathrm{Cl}$ $2 \mathrm{p}$ core level were recorded using a pass energy of $40 \mathrm{eV}$ and a ${ }_{65} \theta=0^{\circ}$ take-off angle (angle between the surface normal and the detection direction). Under the same conditions, the valence band was measured between $9 \mathrm{eV}$ and $-4 \mathrm{eV}$ to take into account any charge neutralizer shift. With a pass energy equal to 160 and 40 $\mathrm{eV}$, the spectral widening of the instrument measured on the 70 silver Fermi edge was 1.9 and $0.55 \mathrm{eV}$ respectively.

In order to achieve the in situ UV illumination, a UV led (Nichia) emitting at $375 \mathrm{~nm}$ with a $3.2 \mathrm{~mW} . \mathrm{cm}^{-2}$ power density, at the sample position, was fixed below the glass slide, in the sample holder. Its polarization, with a $3.5 \mathrm{~V}$ voltage and $25 \mathrm{~mA}$ 75 current, is ensured by the manipulator of the XPS apparatus. Such a configuration allows us to illuminate the sample and control the illumination sequence during the acquisition procedure. Sequences of XPS measurements (30 minutes acquisition and 30 minutes illumination) were conducted for $70 \mathrm{~h}$.

80 The angular dependence of the XPS signal of the different elements was also studied by rotating the sample to $\theta=30,45,60$ and finally back to $0^{\circ}$, in order to check if any chemical modification was induced by the XPS measurement.

All high-resolution spectra were analyzed and fitted with ${ }_{85}$ CasaXPS. $^{30}$ All spectra were calibrated to the binding energy of adventitious carbon at $284.7 \mathrm{eV}$. All data were fitted using a Shirley function for the background and a pseudo-Voigt function with a Lorentzian ratio of $30 \%$ for the various peaks. All parameters were left free during fitting, except for the full widths 90 at half maximum (FWHM) that were kept the same for the different contributions of one element, and this FWHM value was fitted to minimize the refinement uncertainty. ${ }^{31}$

\section{UV-visible spectroscopy}

UV-visible spectra were recorded with a Varian Cary 5G 95 spectrometer between 350 and $1600 \mathrm{~nm}$, with a step of $1 \mathrm{~nm}$. Due to the strong visible absorption of the TiDMF gel, a homemade sample container was built for this experiment: the TiDMF fresh sol was introduced and sealed between two quartz glasses, separated by a spacer of Kapton tape, ensuring an optical pass of 100 the gel of $145 \pm 5 \mu \mathrm{m}$. The TiDMF sol to gel transformation was done in situ in the cell by heating at $70^{\circ} \mathrm{C}$ for $24 \mathrm{~h}$. The obtained TiDMF gel sample was then exposed to a UV lamp (365 nm; 200 $\mu \mathrm{W} \mathrm{cm}$ ) for different lengths of time before recording the data.

\section{Results and discussion}

\section{TiDMF Sol and gel formation mechanism}

The complete mechanism of titanium oxide sol and gel (hereafter denoted as TiDMF) formation, although already detailed in previous studies, ${ }^{25,27,32}$ will nevertheless be iterated below in order to clarify the subsequent results. 

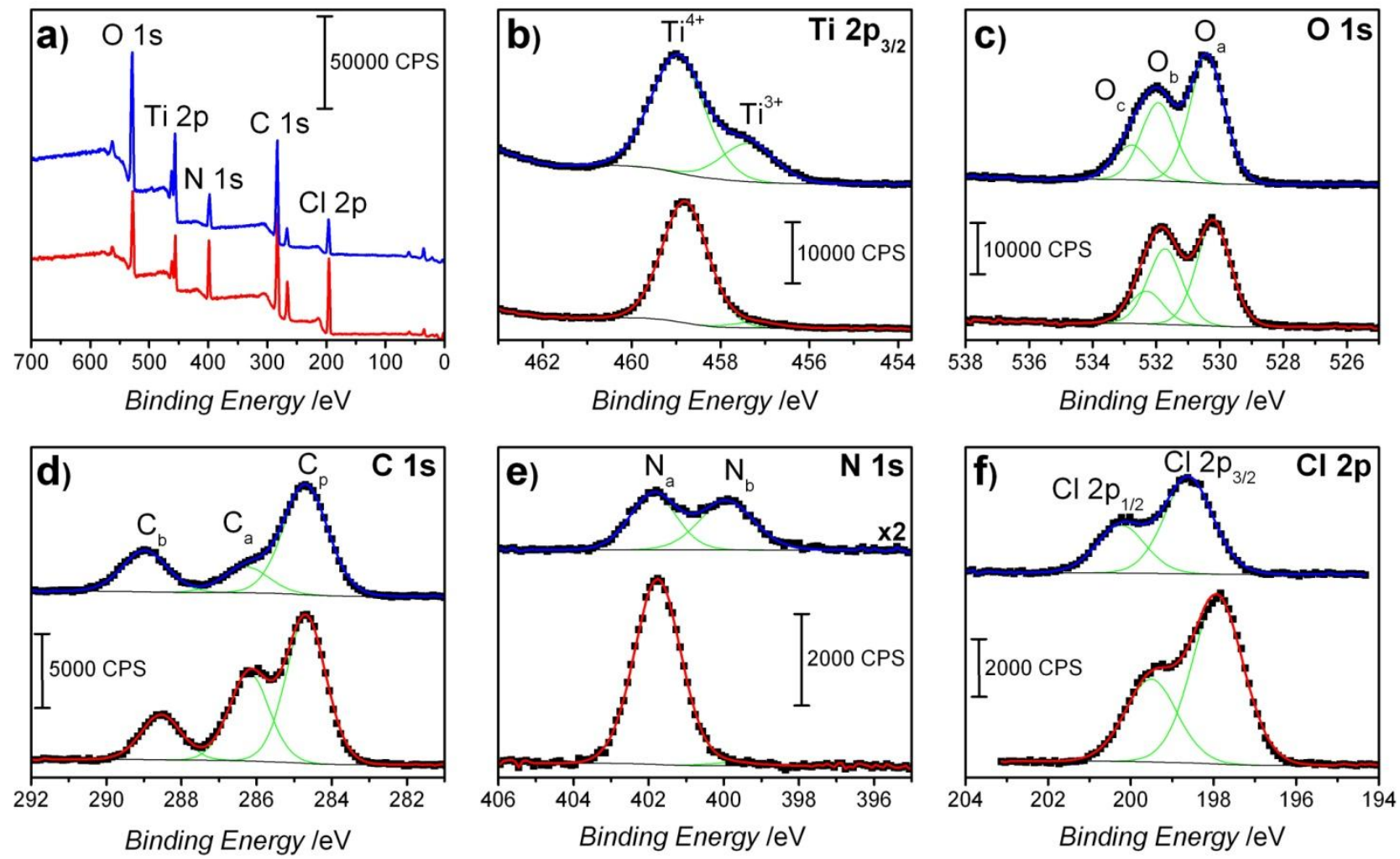

Fig. 1 XPS spectra of TiDMF gel before (red) and after (blue) $34 \mathrm{~h}$ of UV illumination. a) survey spectra and high-resolution spectra of b) Ti $2 \mathrm{p}_{3 / 2}$, c) O 1s, d) $\mathrm{C} 1 \mathrm{~s}, \mathrm{e}) \mathrm{N} 1 \mathrm{~s}$ and $\mathrm{Cl} 2 \mathrm{p}$. Black squares are the experimental data, and bold blue and red lines are the curve fitting results.

When mixing the titanium precursor $\left(\mathrm{TiOCl}_{2}, 1.4 \mathrm{HCl}, 7 \mathrm{H}_{2} \mathrm{O}\right.$; 5 denoted as $\mathrm{TiOCl}_{2}$ ) with DMF, a double hydrolysis takes place: (i) the dimethylformamide is hydrolyzed as dimethylammonium chloride (DMACl) and methanoic acid $(\mathrm{HCOOH}) ;^{33}$ (ii) the hydrolysis of the titanium precursor occurs via olation and oxalation reactions according to equation $1:^{34}$

$10\left(\mathrm{TiOCl}_{2}, 1.4 \mathrm{HCl}, 7 \mathrm{H}_{2} \mathrm{O}\right)+6.4 \mathrm{DMF} \rightarrow$ $\left(\mathrm{TiO}_{2}, \mathrm{zH}_{2} \mathrm{O}\right)_{\text {polymer }}+\mathrm{y} \mathrm{DMACl}+\mathrm{y} \mathrm{HCOOH}+(6.4-\mathrm{y}) \mathrm{DMF}+$ (3.4-y) $\mathrm{HCl}+(6-y-z) \mathrm{H}_{2} \mathrm{O}$

During this slow hydrolysis reaction, the inorganic clusters extend in a bi-dimensional polymeric form of hydrated titanium 15 oxide network, which was determined by transmission electron microscopy (TEM) and X-ray absorption spectroscopy (XAS) experiments. ${ }^{25}$ This polymerisation increases the viscosity of the sol. At the same time, part of the DMF enters into the $\mathrm{Ti}^{4+}$ coordination and is then hydrolyzed as DMACl and $\mathrm{HCOOH}$, or 20 more precisely as the methanoate group coordinating the $\mathrm{Ti}^{4+}$. Taking into account the previous XAS results, XRD and TEM measurements, this allowed us to conclude that DMACl is located between the bi-dimensional titanium oxide layers. ${ }^{25}$ Once all the chlorides have been consumed and the TiDMF sol has turned into $25 \mathrm{a}$ gel, the expected formulation is $\left(\mathrm{TiO}_{2}, \mathrm{zH}_{2} \mathrm{O}\right)_{\text {polymer, }} 3.4$
DMACl, 3.4 HCOOH, 3 DMF, (2.6-z) $\mathrm{H}_{2} \mathrm{O}$.

\section{XPS with in-situ irradiation}

The analysis was conducted using a modified sample holder that integrates a UV LED emitting at $375 \mathrm{~nm}$ for the purpose of in30 situ illumination. The sample is exposed to UV irradiation for a total time of 34 hours and the XPS spectra are periodically recorded every 30 minutes. The chemical composition of the gel and its modifications under UV illumination can thus be monitored.

35 Before introducing the sample into the XPS analysis chamber, the liquid phase is evacuated from the gel by maintaining the preparation in an ultra-high vacuum in the pre-chamber. The analysis is, therefore, conducted solely on the solid part of the photosensitive material, which is comprised of the inorganic 40 titanium oxide network, as well as the surrounding molecules interacting strongly with this inorganic part. These species were identified by Raman ${ }^{27}$ and ${ }^{1} \mathrm{H}$ solid NMR spectroscopies (Suppl. Info. fig.S1), i.e. $\mathrm{HCOO}^{-}$, DMACl...

XPS peaks attribution

${ }_{45}$ As expected, the different elements present in the gel could be detected on the survey spectrum i.e. $\mathrm{O}, \mathrm{Ti}, \mathrm{N}, \mathrm{C}$ and $\mathrm{Cl}$ (figure 1.a). The high-resolution spectra of Ti $2 \mathrm{p}_{3 / 2}, \mathrm{O} 1 \mathrm{~s}, \mathrm{C} 1 \mathrm{~s}, \mathrm{~N} 1 \mathrm{~s}$ and $\mathrm{Cl} 2 \mathrm{p}$, recorded before and after $34 \mathrm{~h}$ of UV illumination, are 
Cite this: DOI: $10.1039 / \mathrm{c} 0 \mathrm{xx} 00000 \mathrm{x}$

www.rsc.org/xxxxxx

ARTICLE TYPE

Table 1 Refinement of the various XPS peaks for a TiDMF gel of $1.42 \mathrm{~mol} . \mathrm{L}^{-1}$ before and after in situ UV illumination for $34 \mathrm{~h}$.

\begin{tabular}{|c|c|c|c|c|c|c|c|}
\hline \multirow{2}{*}{ Core level } & \multicolumn{3}{|c|}{ Before illumination } & \multicolumn{3}{|c|}{ After illumination } & \multirow{2}{*}{ Attribution } \\
\hline & Position (eV) & FWHM (eV) & At. (\%) & Position (eV) & FWHM (eV) & At. (\%) & \\
\hline O 1s & & & 30.9 & & & 42.5 & \\
\hline $\mathrm{O}_{\mathrm{a}} 1 \mathrm{~s}$ & $530.2(1)$ & $1.25(5)$ & $49.6(5)$ & $530.4(1)$ & $1.26(5)$ & $52.1(5)$ & Ti-O-Ti ${ }^{36}$ \\
\hline $\mathrm{O}_{\mathrm{b}} 1 \mathrm{~s}$ & $531.7(1)$ & \multirow{2}{*}{$1.26(5)$} & $36.5(5)$ & $531.9(1)$ & \multirow{2}{*}{$1.54(5)$} & $32.2(5)$ & Ti-O-C, ${ }^{37} \mathrm{Ti}-\mathbf{O H}$ or $\mathrm{Ti}-\mathbf{O H}_{2}{ }^{38}$ \\
\hline $\mathrm{O}_{\mathrm{c}} 1 \mathrm{~s}$ & $532.4(1)$ & & $13.9(5)$ & $532.6(1)$ & & $15.7(5)$ & $\mathbf{C}=\mathbf{O}^{39}$ \\
\hline Ti $2 p_{3 / 2}$ & & & 8.7 & & & 13.9 & \\
\hline $\mathrm{Ti}^{4+} 2 \mathrm{p}_{3 / 2}$ & $458.8(1)$ & \multirow{2}{*}{$1.21(5)$} & 95.5(5) & $459.0(1)$ & \multirow{2}{*}{$1.41(5)$} & 75.3(5) & $\mathbf{T i}^{4+35}$ \\
\hline $\mathrm{Ti}^{3+} 2 \mathrm{p}_{3 / 2}$ & 457.2(1) & & $4.5(5)$ & 457.4(1) & & $24.7(5)$ & $\mathbf{T i}^{3+35}$ \\
\hline N 1s & & & 6.2 & & & 2.1 & \\
\hline $\mathrm{N}_{\mathrm{a}} 1 \mathrm{~s}$ & $401.8(1)$ & \multirow{2}{*}{$1.45(5)$} & $98.3(5)$ & $402.1(1)$ & \multirow{2}{*}{$1.60(5)$} & $53.9(5)$ & $\mathrm{DMACl}^{41}$ \\
\hline $\mathrm{N}_{\mathrm{b}} 1 \mathrm{~s}$ & $399.7(1)$ & & $1.7(5)$ & 400.1(1) & & $46.1(5)$ & DMA $^{41}$ \\
\hline C 1s & & & 46.1 & & & 36.6 & \\
\hline $\mathrm{C}_{\mathrm{p}} 1 \mathrm{~s}$ & $284.7(1)$ & \multirow{3}{*}{$1.24(5)$} & $52.5(5)$ & $284.7(1)$ & \multirow{3}{*}{$1.40(5)$} & $62.0(5)$ & Pollution \\
\hline $\mathrm{C}_{\mathrm{a}} 1 \mathrm{~s}$ & $286.2(1)$ & & $31.4(5)$ & $286.3(1)$ & & $14.7(5)$ & $\mathrm{DMACl}^{40}$ \\
\hline $\mathrm{C}_{\mathrm{b}} 1 \mathrm{~s}$ & $288.6(1)$ & & $16.1(5)$ & $289.0(1)$ & & $23.3(5)$ & C-O (methanoate) ${ }^{37}$ \\
\hline Cl 2p & & & 8.1 & & & 4.9 & \\
\hline $\mathrm{Cl} 2 \mathrm{p}_{1 / 2}$ & 199.5(1) & \multirow{2}{*}{$1.47(5)$} & - & $200.2(1)$ & \multirow{2}{*}{$1.38(5)$} & - & \multirow{2}{*}{ Cl 2p DMACl ${ }^{36}$} \\
\hline $\mathrm{Cl} 2 \mathrm{p}_{3 / 2}$ & 197.9(1) & & - & $198.6(1)$ & & - & \\
\hline
\end{tabular}

The overall atomic composition is in bold font, and the relative percentage of each atom is in normal font..

grouped together in figure 1. Positions, Full Width at Half Maximum (FWHM) and proportions of the different components, 5 before and after illumination, are reported in table 1.

Before UV illumination, the Ti $2 \mathrm{p}_{3 / 2}$ peak at $458.8 \pm 0.1 \mathrm{eV}$ is attributable to $\mathrm{Ti}^{4+}$ cations (figure 1.b). ${ }^{35}$ Due to ultra-high vacuum and/or incident X-ray beam during height adjustment, a small percentage of $\mathrm{Ti}$ cations are reduced to $\mathrm{Ti}^{3+}$ (less than $5 \%$ ) 10 and are visible as a shoulder located at $457.2 \pm 0.1 \mathrm{eV}$. After 34 hours of UV illumination, up to $25 \%$ of the $\mathrm{Ti}^{4+}$ is reduced.

The $\mathrm{O} 1 \mathrm{~s}$ peak (figure 1.c) is decomposed into three components: one at $530.2 \pm 0.1 \mathrm{eV}\left(\mathrm{O}_{\mathrm{a}}\right)$, which is characteristic of oxygen atoms belonging to the Ti-O framework ${ }^{36}$; and two 15 nearby components, $\mathrm{O}_{\mathrm{b}}$ and $\mathrm{O}_{\mathrm{c}}$, located at 531.7 and $532.3 \pm 0.1$ $\mathrm{eV}$, respectively. The binding energy of $\mathrm{O}_{b}$ is characteristic of oxygen atoms involved in Ti-O-C-R bonds, ${ }^{37}$ such as carboxylate species, but also of an $\mathrm{OH}$ group or water molecule coordinating Ti cations. ${ }^{38}$ The higher binding energy of $\mathrm{O}_{c}$ is typical of oxygen 20 from $\mathrm{O}=\mathrm{C}-\mathrm{R}$ bonds that can be attributed to monodentate $\mathrm{HCOO}^{-39}$

Three components are required to fit the $\mathrm{C} 1 \mathrm{~s}$ spectra presented in figure 1.d. The first component being the peak exhibiting the lowest binding energy, which is attributed to adventitious carbon 25 and is calibrated to $284.7 \mathrm{eV}\left(\mathrm{C}_{\mathrm{p}}\right)$. The second component, noted $\mathrm{C}_{\mathrm{a}}$, at $286.2 \pm 0.1 \mathrm{eV}$, is attributed to the carbon of DMACl. ${ }^{40} \mathrm{~A}$ third component, $\mathrm{C}_{\mathrm{b}}$, located at $288.6 \pm 0.1 \mathrm{eV}$ is attributed to the $\mathrm{C}$ atoms bonded to oxygen atoms. This lattermost peak is attributed to the methanoate $\left(\mathrm{HCOO}^{-}\right)$group coordinating $\mathrm{Ti}$ 30 cations, as indicated by IR and Raman spectroscopies. ${ }^{25,27}$

Before illumination, nitrogen atoms mainly appear as one lone component $\left(\mathrm{N}_{\mathrm{a}}\right)$ located at $401.8 \pm 0.1 \mathrm{eV}$, which is assigned to dimethylammonium chloride (DMACl). ${ }^{41}$ The other component $\left(\mathrm{N}_{\mathrm{b}}\right)$, the intensity of which increases with UV illumination time, 35 exhibits a smaller binding energy $(399.7 \pm 0.1 \mathrm{eV})$ and may be attributed to nitrogen atoms related to the amine type, presumably dimethylamine (DMA), that can result from the equilibrium between DMACl and DMA: ${ }^{41}$

$$
\left(\mathrm{CH}_{3}\right)_{2} \mathrm{NH}_{2}^{+}+\mathrm{Cl}^{-} \leftrightarrow\left(\mathrm{CH}_{3}\right)_{2} \mathrm{NH}+\mathrm{HCl}
$$

40 Chlorine atoms are detected as a single contribution typical for $\mathrm{Cl}^{-}$and therefore in agreement with the presence of DMACl.

\section{TiDMF gel composition}

A formulation of the gel can be proposed from the intensities of 45 the different components,according to the following procedure: $\mathrm{N}_{\mathrm{a}}$ and $\mathrm{N}_{\mathrm{b}}$ peak intensities indicate the quantity of DMACl and DMA, respectively; the overall amount of methanoate is evaluated by the $\mathrm{C}_{\mathrm{b}}$ 1s peak intensity; and the quantity of monodentate $\mathrm{HCOO}^{-}$can be deduced from the $\mathrm{O}_{c} 1 \mathrm{~s}$ peak area 50 corresponding to the oxygen of $\mathrm{C}=\mathrm{O}$ bonds. The following chemical formula can thus be proposed for the TiDMF gel sample before illumination (normalized for one Ti atom):

$$
\begin{aligned}
& \mathrm{TiO}_{1.75}(\mathrm{HCOO})_{0.85}+0.71 \mathrm{DMACl}+0.01 \mathrm{DMA}+0.08 \mathrm{O}_{\mathrm{b}}+ \\
& 0.23 \mathrm{C}_{\mathrm{a}}+0.22 \mathrm{Cl}^{-}
\end{aligned}
$$

55 The charge equilibrium between the titanium and the coordinating ligand is not taken into account in this formula and will be discussed in detail in the next section. The Ti/methanoate ratio of 0.85 is fairly coherent with the result deduced from the liquid ${ }^{1} \mathrm{H}$ NMR (1.0). ${ }^{27}$ Approximately half of these methanoate ${ }_{60}$ molecules are in a bidentate conformation. At this stage, DMACl is predominant in the gel. It should be noted that $0.22 \mathrm{Cl}^{-} / \mathrm{Ti}$ is present in excess and cannot be attributed to DMACl. The total amount of $\mathrm{Cl}^{-}(0.93)$ is lower than the expected value of 3.4. This suggests that the dimethylammonium chloride may be partially ${ }_{65}$ decomposed (and evacuated under high vacuum) by the incident $\mathrm{X}$-ray and/or the $\mathrm{e}^{-}$beam of the neutralizer during the initial 


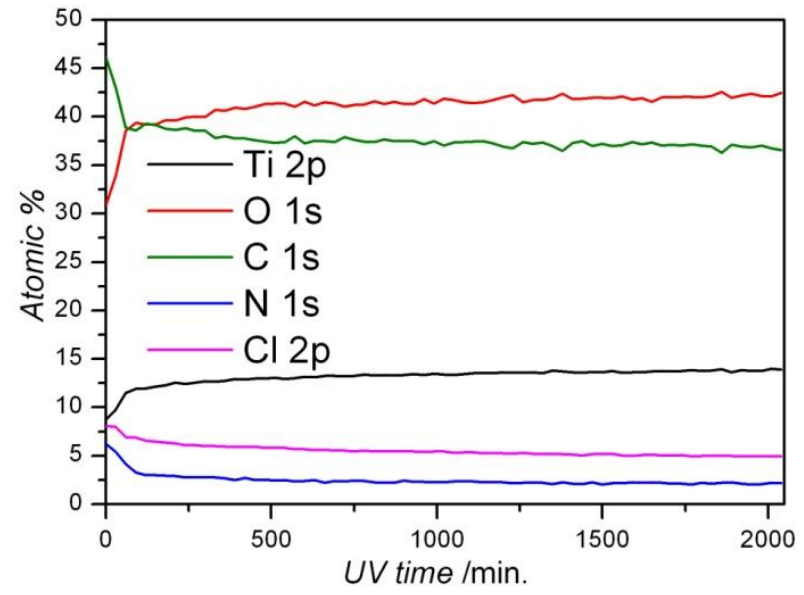

Fig. 2 Evolution of the Ti 2p, $\mathrm{O} 1 \mathrm{~s}, \mathrm{C} 1 \mathrm{~s} \mathrm{~N} 1 \mathrm{~s}$ and $\mathrm{Cl} 2 \mathrm{p}$ composition of the TiDMF gel under UV illumination.

adjustments of the experiment.

5 Considering the stoichiometry of the different components, XPS results indicate an excess of $\mathrm{C}_{\mathrm{a}}$ and $\mathrm{O}_{\mathrm{b}}(0.23$ and 0.08$)$ that could be linked to the adsorption of some organic residue on the surface, resulting from the degradation of methanoate, $\mathrm{N}, \mathrm{N}$ dimethyformamide or DMACl under electron and X-ray 10 irradiation.

Using the same methodology, the following composition can be proposed at the end of the experiment, i.e. after $34 \mathrm{~h}$ of UV illumination:

$\mathrm{TiO}_{1.59}(\mathrm{HCOO})_{0.61}+0.08 \mathrm{DMACl}+0.07 \mathrm{DMA}+0.23 \mathrm{O}_{\mathrm{b}}+$ ${ }_{15} 0.08 \mathrm{C}_{\mathrm{a}}+0.27 \mathrm{Cl}^{-}$

In this case, the amount of methanoate is decreased by a third when compared to the beginning of the experiment, and the ratio of this methanoate in a bidentate conformation decreases to $22 \%$. The quantity of DMACl also decreases, whereas an increase in 20 the intensity of the $\mathrm{N}_{\mathrm{b}} 1 \mathrm{~s}$ peak attributed to dimethylamine is observed. An excess of $\mathrm{O}_{b} 1 \mathrm{~s}, \mathrm{C}_{\mathrm{a}} 1 \mathrm{~s}$ and $\mathrm{Cl} 2 \mathrm{p}$ is measured when compared to the determined amounts of methanoate, DMA and DMACl species respectively.

\section{TiDMF gel evolution under illumination}

${ }_{25}$ In order to get more insight into the mechanisms involved in these modifications, we studied the evolution of atomic composition during the in-situ illumination experiment (figure 2). The detailed elemental evolution of each contribution is presented in the supplementary information section (figure S3). During the 30 first steps $(\mathrm{t}<120 \mathrm{~min}$.) of illumination, a rapid increase of the $\mathrm{Ti}$ $2 \mathrm{p}_{3 / 2}$ and $\mathrm{O} 1 \mathrm{~s}$ peaks is observed, which is correlated to the decrease of the $\mathrm{N} 1 \mathrm{~s}, \mathrm{Cl} 2 \mathrm{p}$ and $\mathrm{C} 1 \mathrm{~s}$ contributions. Regarding the carbon, the $\mathrm{C}_{\mathrm{p}}$ and $\mathrm{C}_{\mathrm{a}}$ contributions are mainly affected by UV illumination, as presented in figure S3.b. This initial rapid 35 evolution suggests a degradation of crystallized DMACl. Angular-dependant XPS analysis was conducted in order to clarify the location of DMACl and its degradation mechanism. The results, detailed in the supplementary information section (figure S4), confirm that the DMACl is not homogeneously 40 distributed within the thickness of the TiDMF gel, but is instead largely crystallized at the very surface. It also confirms that $\mathrm{DMACl}$ is degraded under $\mathrm{X}$-ray irradiation, generating
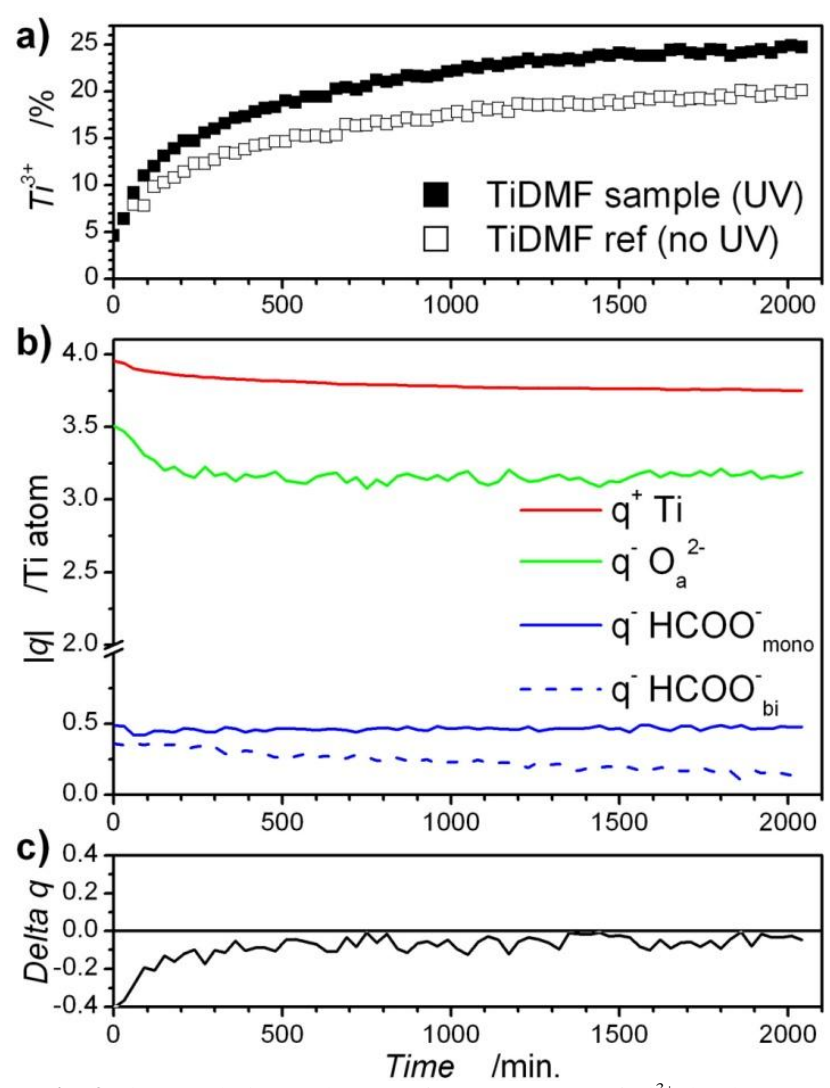

Fig. 3 Time evolution under UV of: a) percentage of $\mathrm{Ti}^{3+}$; b) charges 45 carried by Ti cations, $\mathrm{O}^{2-}, \mathrm{HCOO}^{-}$monodentate and bidentate (the charges are normalized for $1 \mathrm{Ti}$ cation); and c) charge balance between cationic and anionic species.

dimethylamine and $\mathrm{HCl}$ as dissociation products.

During UV illumination, the sample presents a blue coloration 50 confirming that the photosensitivity of the gel is related to the solid nanometric part of the gel and does not involve DMF, which is evacuated under vacuum. The evolution of the percentage of reduced $\mathrm{Ti}^{3+}$ titanium in relation to the illumination time is presented in figure 3.a. By way of comparison, the evolution of ${ }_{55}$ the $\mathrm{Ti}^{3+}$ percentage for a sample measured according to the same protocol, but without UV illumination, is also presented. With regards to the sample exposed to $\mathrm{UV}$, up to $25 \%$ of $\mathrm{Ti}^{4+}$ is reduced to $\mathrm{Ti}^{3+}$ after $34 \mathrm{~h}$ of irradiation, whereas for the reference sample the reduction reaches $20 \%$. One could conclude that only ${ }_{60} 5 \%$ of the reduction is induced by UV illumination, but in fact the mechanism seems to be more complex: for a sample subjected to $\mathrm{UV}$ for $34 \mathrm{~h}$, but not exposed to the X-rays or electrons of the neutralizer, XPS measurement conducted just after the illumination indicates that $15 \%$ of the titanium was photoreduced. ${ }_{65}$ It should be noted that the $\mathrm{Ti}^{3+}$ formation under the influence of a high vacuum can be excluded, since the ratio remains close to $5 \%$ for an area of the sample that is not exposed to UV, X-rays or electrons.

From the composition of the TiDMF gel, the charge balance in 70 the inorganic part can be assessed. To this effect, an average positive charge is calculated for one Ti cation in function of the ratio $\mathrm{x}$ of $\mathrm{Ti}^{3+}$ according to:

$\mathrm{q}^{+}=4(1-\mathrm{x})+3 \mathrm{x}$ 
The negative charges of titanium cation ligands are calculated considering a charge of -2 for the $\mathrm{O}_{\mathrm{a}} 1 \mathrm{~s}$ atoms and -1 for methanoates. The partial charges attributed to oxygen, methanoate and titanium (normalized for one Ti atom), as well as 5 the charge balance between cationic and anionic species, are represented in figures 3.b and 3.c. During the first 120 minutes of UV illumination, a rapid decrease of the charge related to $\mathrm{O}_{a} 1 \mathrm{~s}$ is observed. After this period, this charge stays almost constant at $3.16 \mathrm{q}$ per $\mathrm{Ti}$ atom, which corresponds to 1.58 oxo type atoms 10 coordinating the titanium. The overall number of methanoate species coordinating titanium continuously decreases over time. Aside from the first 120 minutes of illumination, the charge balance between Ti cations and their ligands is quite good and the average difference between negative and positive charges is less 15 than $2 \%$.

Upon illumination, the other species present in the gel are affected and the evolution of these peaks can be monitored in order to obtain further information about the photochemical mechanism. As presented in figure 4.a, the number of 20 methanoates coordinating the titanium cation decreases with UV illumination time, suggesting that methanoate species are involved in the TiDMF gel photoreduction process. According to Dielbold, oxygen atoms that are formed during the decomposition of methanoates are inserted into the lattice via reaction with ${ }_{25} \mathrm{Ti}^{3+}{ }^{42}$ The other fragments, such as $\mathrm{CO}$, would desorb. By analogy with studies conducted on $\mathrm{TiO}_{2}$ crystalline surfaces, a mechanism including several steps can be proposed for TiDMF gel:

Firstly, there is a change of the $\mathrm{HCOO}^{-}$conformation from 30 bidentate to monodentate around the $\mathrm{Ti}^{3+}$ site, assisted by photogenerated holes:

$\mathrm{O}_{\mathrm{s}}-\mathrm{CH}-\mathrm{O}_{\mathrm{s}}^{-}+\mathrm{h}^{+} \rightarrow \mathrm{HCOO}_{\mathrm{s}}^{-}+\square_{\mathrm{Os}^{+}}$

In this equation $\mathrm{O}_{\mathrm{s}}$ and $\square_{\mathrm{Os}}{ }^{+}$stand for $\mathrm{O}$ atoms at the surface of the Ti-O-Ti network, and a positively charged oxygen vacancy, 35 respectively. From XPS experiments, the ratio of monodentate methanoate to overall methanoate is calculated according to $\mathrm{O}_{c}$ $1 \mathrm{~s} / \mathrm{C}_{\mathrm{b}} 1 \mathrm{~s}$. Its evolution versus the percentage of $\mathrm{Ti}^{3+}$ formed is plotted in figure 4.b. It appears that if the overall methanoate decreases, the proportion of monodentate methanoate increases 40 from 0.5 to 0.8 , approximately, according to the mechanism of equation 6.

Secondly, we observe a dissociative reaction of monodentate methanoate into surface hydroxyls and $\mathrm{CO}$, which is desorbed under vacuum:

${ }_{45} \mathrm{HCOO}_{\mathrm{s}}^{-} \rightarrow \mathrm{CO}_{\mathrm{g}}+\mathrm{OH}_{\mathrm{s}}^{-}$

As observed in figure 4.a, the number of oxygen $\mathrm{O}_{\mathrm{b}} 1 \mathrm{~s}$ in excess, i.e. that which cannot be attributed to Ti-O-C atoms of $\mathrm{HCOO}_{\mathrm{s}}$ coordinating titanium, is increasing. These atoms can be attributed to the $\mathrm{OH}_{\mathrm{s}}$ groups coordinating titanium, and this 50 would confirm that the methanoate species are being substituted by hydroxo groups at the surface of the inorganic part of the TiDMF gel, as previously observed by EPR. ${ }^{[28]}$ Furthermore, the rates of $\mathrm{HCOO}^{-}$decrease and of excess $\mathrm{O}_{b}$ increase are really close (-9.4 10 $0^{-5} \mathrm{HCOO}^{-} \cdot \mathrm{min}^{-1}$ and $9.710^{-5} \mathrm{O}_{\mathrm{b}} \cdot \mathrm{min}^{-1}$; Fig. 5.a), in 55 agreement with the mechanism described in equation 7.
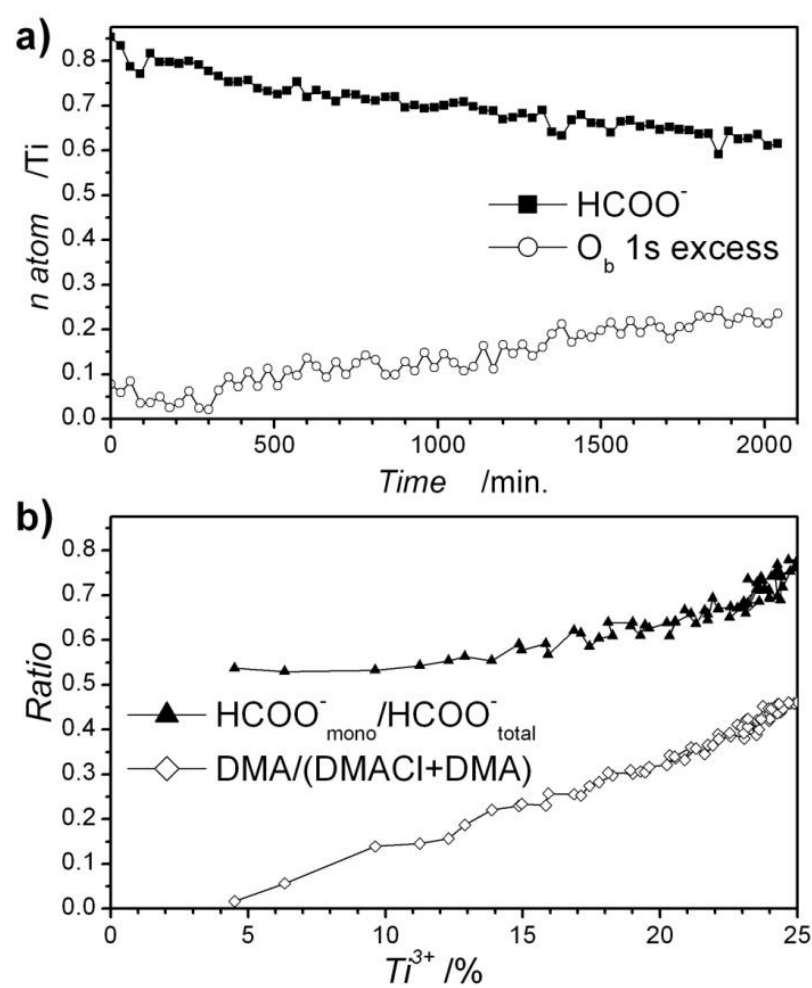

Fig. 4 a) Evolution of the quantity of $\mathrm{HCOO}^{-}$and of $\mathrm{O}_{\mathrm{b}} 1 \mathrm{~s}$ in excess in the TiDMF gel with the UV illumination time; b) Ratio of amine-type nitrogen over overall nitrogen, and ratio of monodentate type methanoate 60 versus the percentage of reduced titanium.

Thirdly, even though the role of dimethylammonium chloride is not clear at this point in our study, we infer that it dissociates in dimethylamine and hydrochloride, according to the mechanism of equation 2 . The released chlorides interact with the solid part of 65 the gel, probably with the vacant sites generated according to eq. 6 , as already evidenced by theoretical and experimental studies on $\mathrm{TiO}_{2}$ surfaces. ${ }^{43}$ Indeed, whereas $90 \%$ of the dimethylamine is evacuated under vacuum, only $60 \%$ of the initial quantity of $\mathrm{Cl}^{-}$ measured by XPS is missing at the end of the reaction. 70 Furthermore, the ratio of $\mathrm{N} 1 \mathrm{~s}$ attributed to dimethylamine compared to the overall $\mathrm{N} 1 \mathrm{~s}$ content is calculated according to $\left(\mathrm{N}_{\mathrm{b}} /\left(\mathrm{N}_{\mathrm{a}}+\mathrm{N}_{\mathrm{b}}\right)\right)$, and is reported in figure 4.b. It appears that the ratio of DMA type nitrogen increases linearly with the photoreduction of titanium, thus supporting the hypothesis of 75 dimethylammonium chloride deprotonation. Nevertheless the linear evolution has to be interpreted with caution as dimethylamine is removed from the surface due to the ultra-high vacuum, and thus only part of this product is taken into account during the measurement.

80 To summarize, the proposed UV light absorption mechanism of the TiDMF gel implies the generation of an electron-hole pair. Initially, it is mainly the methanoate species that coordinate titanium cations, and the remnant organic part is essentially constituted of DMACl. Under UV illumination, the hole is 85 involved in the mechanism that changes the organic ligands, inducing several modifications. One such modification is that the methanoate species change their coordination from bidentate to monodentate, leaving oxygen vacancies at the surface of the inorganic part of the gel. Also, part of the methanoate is 


\section{Cite this: DOI: 10.1039/c0xx00000x}

\section{WwW.rsc.org/xxXXXX}

ARTICLE TYPE
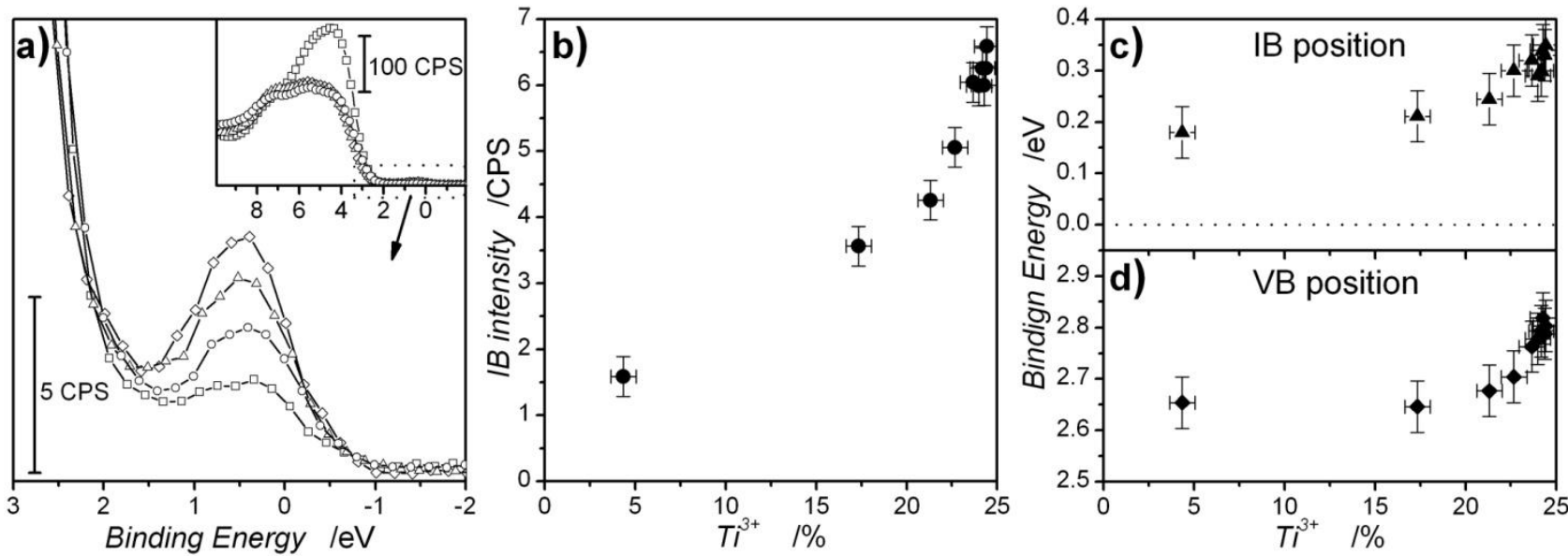

Fig. 5 a) Evolution of the valence band with illumination time (inset), including a zoom of the region between the Fermi level and the valence band ( $\square$ : before illumination; $\circ: 360 \mathrm{~min} ; \Delta: 1440 \mathrm{~min} ; \diamond .2520 \mathrm{~min}$ UV illumination); b) Intermediate Ti $3 \mathrm{~d}$ band intensity; c) Position versus the amount of Ti ${ }^{3+}$ formed in the gel; and d) Valence band position.

5 decomposed and removed under vacuum, inducing changes in the coordination species of the titanium cation, and these methanoate species are substituted by hydroxo groups. ${ }^{28}$ At the same time, a dissociation of dimethylammonium chloride occurs as the chlorides are required to stabilize the photogenerated vacancies at 10 the surface of the inorganic part of the TiDMF gel, and the resulting dimethylamine molecules are evacuated under vacuum. Lastly, it can also be noted that the photogenerated electron is promoted to the empty $3 \mathrm{~d}$ orbital of $\mathrm{Ti}^{4+}$, which is then reduced to $\mathrm{Ti}^{3+}$, and since the hole is involved in the oxidation of 15 methanoate, the electron can be stabilized on this orbital and does not recombine.

\section{Intermediate band generation under UV illumination}

These phenomena are associated with the appearance of an intermediate band located between the Fermi level $(0 \mathrm{eV}$ binding 20 energy) and the top of the valence band that can be observed by XPS measurements (figure 5.a). The intensity of the IB increases depending on the UV illumination time and thus the amount of photoreduced titanium (figure 5.b). Initially, when only $5 \%$ of $\mathrm{Ti}^{3+}$ is formed, the band is located at $0.2(1) \mathrm{eV}$ below the Fermi 25 level. When the $\mathrm{Ti}^{3+}$ ratio increases, the position of the IB increases to $0.4(1) \mathrm{eV}$ as presented in figure 5.c. A similar observation can be made for the top of the valence band position, determined by the intercept with 0 of the linear part of the VB from figure 5.a. At first, the valence band is located at 2.6(1) eV 30 below the Fermi level, and then this value increases to $2.8(1) \mathrm{eV}$. The measured position of the IB from the top of the VB is close to the Fermi level and almost constant displaying an average value of $2.45(5) \mathrm{eV}$. This intermediate state can be attributed to a splitting of the titanium $3 \mathrm{~d}$ orbitals of the TiDMF gel. As for the $35 \mathrm{TiO}_{2}$ crystalline structure, the bottom of the CB of the TiDMF gel is presumably mainly constituted of these $\mathrm{Ti} 3 \mathrm{~d}$ orbitals. The nanometric dimension of the inorganic part of the gel, coupled with the anionic substitution on the TiO framework, ${ }^{25}$ allow for the stabilization of a distorted octahedral environment around the ${ }_{40} \mathrm{Ti}$ cations and due to Jahn-Teller effect, allow a splitting of the $\mathrm{T}_{2 \mathrm{~g}}$ orbital. Furthermore, the crystal field is extremely sensitive to the configuration of ligands and the splitting changes when the oxygen atoms are substituted by chlorine atom. Such a splitting of the $\mathrm{T}_{2 \mathrm{~g}}$ orbitals was already observed by EPR experiment. ${ }^{28}$

45 Based on these evidences and due to the partial filling of these intermediate states by one $\mathrm{d}$ electron of $\mathrm{Ti}^{3+}$ ( $3 \mathrm{~d}^{1}$ configuration) the Fermi level should lie in this intermediate band.

\section{Light absorption properties of TiDMF gel}

Under atmospheric pressure, similarly to the solid part of the gel 50 under vacuum, TiDMF gel becomes dark blue upon UV illumination, as illustrated in figure 6.a. Such a dark blue colour was already observed in the case of Titanium bronzes ${ }^{44}$ or Titanium sub-oxides, ${ }^{45}$ with low content of $\mathrm{Ti}^{3+}(<5 \%)$. The UVvisible absorption spectra for a thin layer of TiDMF gel irradiated 55 under UV for different periods of time are grouped together in figure 6.b. Without UV illumination, the spectrum of a gel is characteristic of a semiconductor material with an absorption threshold of around 3.29(5) eV. This value is consistent with the results obtained for $\mathrm{TiO}_{2}$ nanoparticles. ${ }^{46}$ After illumination of 60 the gel, an absorption band appears at a lower energy, centered around approximately $1.3 \mathrm{eV}$. This band reaches a maximum after 48 hours of illumination and is quite intense: between 90 (at $2.5 \mathrm{eV}$ ) and $99 \%$ (at $1.3 \mathrm{eV}$ ) of the light in the visible domain is absorbed. The absorption at high energy is also modified and the 65 absorption threshold is red-shifted towards a lower energy when the illumination time increases. The shape of the absorption spectra at high energy is more complex than that of the nonirradiated TiDMF gel, and seems to be composed of several distinct absorption processes that should reflect the position of 70 the IB measured by XPS. In order to clarify these absorption spectra, they were analyzed according to the Tauc equation: ${ }^{47}$ 
a)

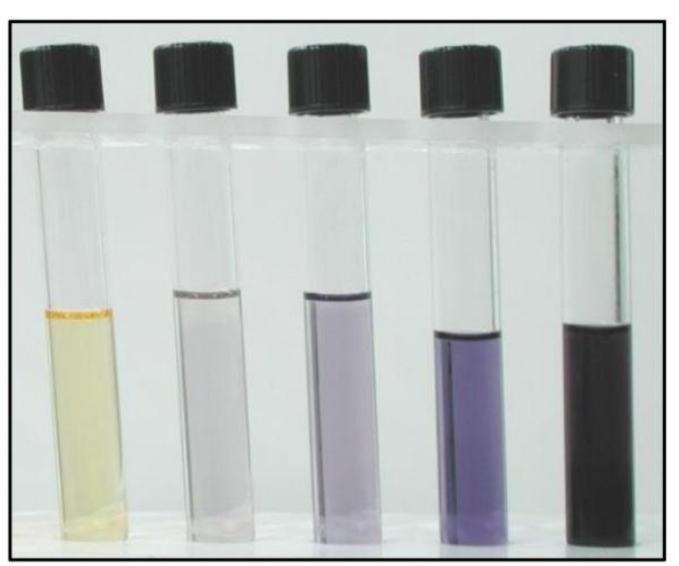

c)

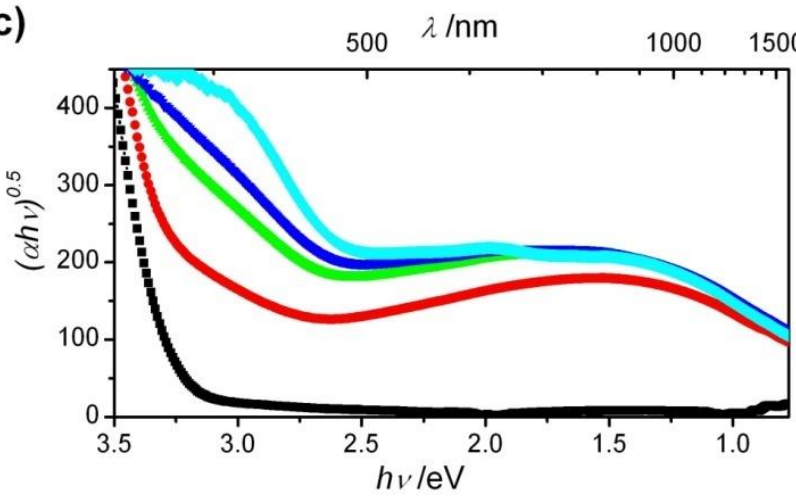

b)

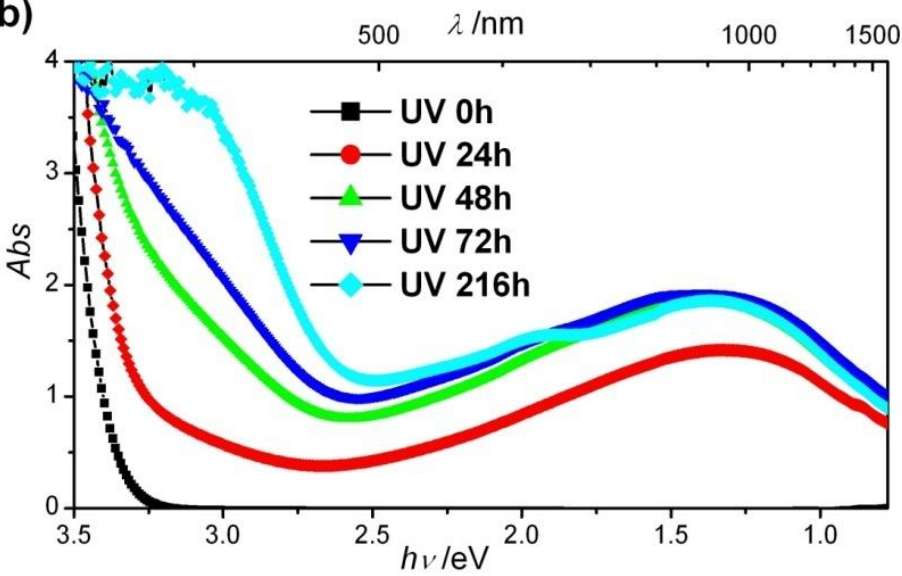

d)

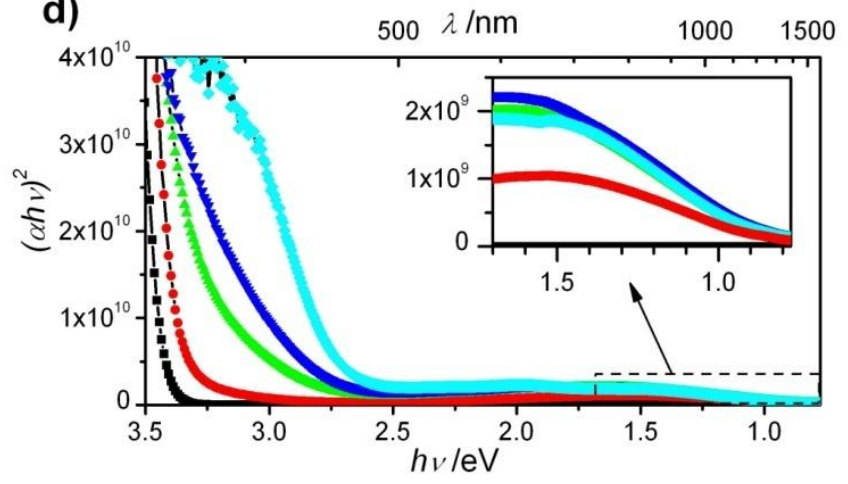

Fig. 6 a) Blue coloration of the TiDMF gel exposed to increasing UV periods (from left to right); b) UV-visible spectra of TiDMF gel exposed to different illumination times; c) and d) Corresponding Tauc plot for TiDMF gel with $\mathrm{n}=0.5$ (c), and n=2 (d).

Table 2. Values of the different gaps determined from the Tauc plots.

\begin{tabular}{c|c|c|c}
\hline UV time $(\mathrm{h})$ & VB to CB $(\mathrm{eV})$ & VB to IB $(\mathrm{eV})$ & IB to CB $(\mathrm{eV})$ \\
\hline 0 & $3.29(5)$ & - & - \\
24 & 3.29 & $2.58(5)$ & $0.84(5)$ \\
48 & 3.29 & $2.52(5)$ & $0.84(5)$ \\
72 & 3.29 & $2.53(5)$ & $0.83(5)$ \\
216 & 3.29 & $2.59(5)$ & $0.86(5)$
\end{tabular}

${ }_{5}(\alpha h v)^{\mathrm{n}}=\mathrm{a}\left(\mathrm{h} v-\mathrm{E}_{\mathrm{g}}\right)$

Where a, $\alpha$ and $E_{g}$ are a proportionality coefficient, the absorption coefficient of the TiDMF gel for each wavelength, and the gap of the gel, respectively. The coefficient $n$ is 2 for an authorized direct transition, and 0.5 for an authorized indirect 10 transition. By plotting $(\alpha h v)^{\mathrm{n}}=\mathrm{f}(\mathrm{h} v)$, the band gap, $\mathrm{E}_{\mathrm{g}}$, can be placed at the intercept of the linear part of the curve with $y=0$. The plots obtained for the direct and indirect transitions are presented in figures 6.c and 6.d. In order to identify the different transitions, the spectra are subtracted from the contribution of the 15 non-irradiated TiDMF gel in order to remove the absorption associated with the transition from the VB to the CB band. The absorption at low energy is fitted by Gaussian peaks and is also removed from the spectra in order to retain only the second absorption threshold, corresponding to the transition between the 20 electronic states at the top of the VB and IB (details of the processes involved can be found in the supplementary information section). The data are treated according to the Tauc formula for an indirect transition $(n=0.5)$. It should be noted that the treatment with $n=2$ results in small linear domains, and the 25 obtained values present a high discrepancy. Using the same method, the energy of the transition between the IB and the lowest energy states of the $\mathrm{CB}$ can be determined to be in the low energy absorption band. In this case, the Tauc model for a direct transition should be used since the values established with $n=0.5$ 30 are negatives. The energies ascertained for these two transitions are shown in table 2.

The energies of the transition attributed to absorption between the VB and the IB are fairly constant, with an average value of $2.55 \mathrm{eV}$ which is close to the value of $2.45 \mathrm{eV}$ determined by ${ }_{35}$ XPS experiments. The results for the IB to CB transition are almost constant, at $0.84(5) \mathrm{eV}$. The sum of these two intermediate transitions is equal to $3.39 \mathrm{eV}$, which is slightly above the value determined for the gap of the non-irradiated TiDMF gel. This difference can be explained by the fact that the Tauc model is 40 usually valid for isotropic materials, whereas in this instance, the 


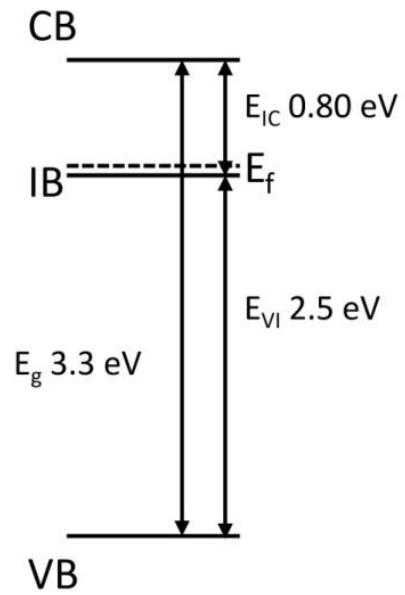

Fig. 7 Proposed band structure for the TiDMF gel after appearance of the intermediate band under UV illumination.

layered and polymeric nature of the TiDMF gel can induce 5 anisotropy. ${ }^{46}$

Using the data obtained from XPS and UV-visible spectroscopy, a schematic electronic band structure can be proposed in order to clarify the position of the intermediate band in the TiDMF gel, as illustrated in figure 7.

\section{${ }_{10}$ Conclusions}

We synthesized a new hybrid organic-inorganic material based on titanium oxide units, using a low temperature sol gel process. XPS characterization of the solid part under in situ UV illumination, allows us to study the photochemical modifications 15 induced on the different parts of the gel. The UV light induces a photoreduction of $\mathrm{Ti}^{4+}$ to $\mathrm{Ti}^{3+}$ in large quantities (up to $25 \%$ of $\mathrm{Ti}^{3+}$ formed), along with a blue coloration of the gel. This process is also accompanied by changes on the organic part of the gel: the methanoate species in the coordination of Ti cations change from 20 a bidentate to monodentate conformation, and some of them are substituted with hydroxyl groups. Concurrently, the $-\mathrm{NH}_{2}{ }^{+}$of DMACl are converted into $-\mathrm{NH}$, in order to deliver the chloride atoms that are required to stabilize these changes. These two phenomena allow for the stabilization of the photogenerated 25 electron on the titanium $3 d$ orbitals. XPS spectra are quite sensitive to the local distortion and intermediate electronic states appear in the gap just below the Fermi level of the material. This band is believed to result from the large splitting between the $T_{2 g}$ orbitals that can be obtained by way of the nanodimensions of the

30 inorganic part of the gel and oxygen substitution by chlorine atom. The position of this partially filled intermediate band located at $2.5 \mathrm{eV}$ above the VB, was determined by XPS and UV visible experiments.

The presence of this band induces strong visible light 35 absorption of the TiDMF gel. The analysis of the UV-visible absorption spectra allows us to measure the energy of the different transitions provided by this intermediate band. The results concerning the determined position are in good agreement with those obtained by XPS experiments, and allow us to build a 40 complete energy diagram for the TiDMF gel.

This new hybrid TiDMF gel heralds a new class of material that can be used in intermediate band solar cells. Among its advantages are that it exhibits the intermediate band at room temperature, and that its one-step preparation by a sol gel process 45 is compatible with low-cost deposition technologies such as printing or spin coating.

\section{Acknowledgements}

T. C. is indebted to the CNRS and the region Pays de la Loire for is grant. Dr N. Dupré is thanked most gratefully for the ${ }^{1} \mathrm{H}$ solid 50 state NMR experiments. This project was funded by the ANR through the OxTiMIB program.

\section{Notes and references}

${ }^{a}$ Institut des Matériaux Jean Rouxel (IMN) Université de Nantes/CNRS,

2 rue de la Houssinière, 44322 Nantes, France.

55 Fax: +33(0)2 403739 95; Tel: +33 (0)2 403739 39;

E-mail: mireille.richard@cnrs-imn.fr

${ }^{b}$ Institut de Chimie et Procédés pour l'Energie, l'Environnement et la Santé (ICPEES) Université de Strasbourg/CNRS,

25 rue Becquerel, 67087 Strasbourg, France.

60 Fax: +33 (0)368 8527 61; Tel: +33(0)368 852737 ;

E-mail: cottineau@unistra.fr

${ }^{c}$ Nanobiotix,

60 rue de Wattignies, B, 75012 Paris, France.

$65 \dagger$ Electronic Supplementary Information (ESI) available: ${ }^{1} \mathrm{H}$ solid state NMR spectra of TiDMF gel: evolution of $\mathrm{C} 1 \mathrm{~s}, \mathrm{O}$ 1s and $\mathrm{N}$ 1s XPS components under UV illumination; angle resolved XPS spectra; model for the UV-visible spectra treatment. See DOI: 10.1039/b000000x/

1 N. S. Lewis, G. Crabtree, in Basic research Needs for solar utilization, Office of Science, U. S. Department of Energy, Washington, DC, 2005.

2 N. S. Lewis, Science, 2007, 315, 798

3 W. Shockley and H. J. Queisser, J. Appl. Phys. 1961, 32, 510.

4 B. S. Richards, Sol. Energy Mater. Sol. Cells, 2006, 90, 1189.

5 H.-Q. Wang, M. Batenschuk, A. Osvet, L. Pinna and C. J. Brabec, Adv. Mat. 2011, 23, 2675.

6 S. J. Kim, W. J. Kim, A. N. Cartwright and P. N. Prasad, Appl. Phys. Lett. 2008, 92, 191107.

7 H. Cotal, C. Fetzer, J. Boisvert, G. Kinsey, R. King, P. Hebert, H. Yoon and N. Karam, Energy Environ. Sci. 2009, $2,174$.

8 NREL website, Best Research-Cell Efficiencies Chart (rev. august2013).

9 A. Luque and A. Marti, Adv. Mat. 2010, 22, 160.

10 A. Luque and A. Marti, Phys. Rev. Lett. 1997, 78, 5014.

11 A. Luque, A. Marti, C. R. Stanley, N. Lopez, L. Cuadra, D. Zhou and A. Mc-Kee, J. Appl. Phys. 2004, 96, 903.

12 A. Marti, E. Antolin, C. R. Stanley, C. D. Farmer, N. Lopez, P. Diaz, E. Canovas, P. G. Linares and A. Luque, Phys. Rev. Lett. 2006, 97, 247701.

13 A. Luque, A. Marti and C. R. Stanley, Nat. Photonics, 2012, 6, 146.

14 H. Pan, B. H. Gu, G. Eres and Z. Y. Zhang, J. Chem. Phys. 2010, 132, 104501.

15 N. Lopez, L. A. Reichertz, K. M. Yu, K. Campman and W. Walukiewicz, Phys. Rev. Lett. 2011, 106, 028701.

16 R. W. Peng, M. Mazzer, K. W. J. Barnham, Appl. Phys. Lett. 2003, 83, 770 .

17 F. Wu. H. Lan, Z. Zhang, and P. Cui, J. Chem. Phys. 2012, 137, 104702.

18 J. Burschka, N. Pellet, S.-J. Moon, R. Humphry-Baker, P. Gao, M. K. Nazeeruddin and M. Grätzel, Nature, 2013, 499, 316.

19 A. Fujishima, X. Zhang and D. A. Tryk, Surf. Sci. Rep. 2008, 63, 515.

20 X. Chen, C. Li, M. Grätzel, R. Kostecki and S. S. Mao, Chem. Soc. Rev. 2012, 41, 7909. 
21 A. Heller, Acc. Chem. Res. 1995, 28, 503.

22 A. Fujishima and K. Honda, Nature, 1972, 238, 37.

23 B. O'Regan and M. Graëtzel, Nature, 1991, 353, 737.

24 T. L. Thompson and J. T. Jr. Yates, Chem. Rev. 2006, 106, 4428.

25 T. Cottineau, M. Richard-Plouet, A. Rouet, E. Puzenat, H. Sutrisno, Y. Piffard, P-E. Petit and L. Brohan, Chem. Mater., 2008, 20, 1421.

26 B. Pattier, M. Henderson, G. Brotons and A. Gibaud, J. Phys. Chem. $B, 2010,114,5227$.

27 T. Cottineau, M. Richard-Plouet, J-Y. Mevellec and L. Brohan, J. Phys. Chem. C, 2011, 115, 12269.

28 T. Cottineau, L. Brohan, M. Pregelj, P. Cevc, M. Richard-Plouet and, D. Arčon, Adv. Func. Mat. 2008, 18, 2602.

29 B. Pattier, M. Henderson, A. Pöppl, A. Kassiba and A. Gibaud, $J$. Phys. Chem. B, 2010, 114, 4424.

30 N. Fairley, Copyright $\odot 2005$ Casa Software Ltd.

31 R. Hesse, T. Chassé, P. Streubel and R. Szargan, Surf. Inter. Anal. 2004, 36, 1373.

32 H. Terisse, A. F. Bando, T. Cottineau, L. Brohan and M. RichardPlouet, J. Sol-Gel Sci. Technol. 2013, 67, 288.

33 S. Liu, C. Wang, H. Zhai and D. Li, J. Mol. Struct. 2003, 654, 215.

34 R. S. Brown, A. J. Bennet and H. Slebocka-Tilk, Acc. Chem. Res. 1992, 25, 481.

35 A. N. Shultz, W. Jang, W. M. Hetherington III, D. R. Baer, L. Q. Wang and M. H. Engelhard, Surf. Sci., 1995, 339, 114; F. Guillemot, M. C. Porté, C. Labrugère and C. Baquey, J. Coll. \& Interf. Sci. 2002, 255, 75.

36 J. F. Moulder, W. F. Stickle, P. E. Sobol and K. D. Bomben in Handbook of X-ray Photoelectron Spectroscopy, Perkin-Elmer Corp.: Eden-Prairie MN, 1992.

37 L. Q. Wang, K. F. Ferris, A. N. Shultz, D. R. Baer and M. H. Engelhard, Surf. Sci. 1997, 380, 352; M. R. Alexander, G. Beamson, C. J. Blomfield, G. Leggett and T. M. Duc, J. Electr. Spectr. Rel.Phen. 2001, 121, 19.

38 J. C. Yu, L. Z. Zhang, Z. Zheng and J. C. Zhao, Chem. Mater. 2003, 15, 2280; Y. F. Gao, Y. Masuda and K. Koumoto, Langmuir, 2004, 20, 3188 .

39 B. J. Meenan, J. A. Hewitt and N. M. D. Brown, Surf. Inter. Anal. $1992,18,187$.

40 D. Briggs and J. T. Grant, in Surface analysis by Auger and X-ray photoelectron Spectroscopy, IM publication, Chichester, 2003.

41 I. V. Chernyshova, K. Hanumantha Rao, A. Vidyadhar and A. V. Shchukarev, Langmuir, 2000, 16, 8071; A. Vidyadhar, K. H. Rao, I. V. Chernyshova and K. S. E. Forssberg, J. Coll. \& Interf. Sci., 2002, 256, 59; A. Vidyadhar, K. H. Rao and I. V. Chernyshova, Coll. \& Surf. A, 2003, 214, 127.

42 U. Diebold, Surf. Sci. Rep. 2003, 48, 53.

43 D. Vogtenhuber, R. Poducky, J. Redinger, E.L.D. Hebenstreit and U. Diebold, Phys. Rev. B 2002, 65, 125411.

44 L. Brohan, R.Marchand, M. Tournoux, J. Solid State Chem., 1988, 72, 145.

45 S. Andersson, A. Magneli, Naturwiss 1956, 43, 495.

46 S. Monticone, R. Tufeu, A. V. Kanaev, E. Scolan and C. Sanchez, Appl. Surf. Sci. 2000, 162, 565.

47 J. I. Pankove in Absorption in opt. proc. semiconductors, PrenticeHall, Englewood Cliffs, NJ, 1971. 